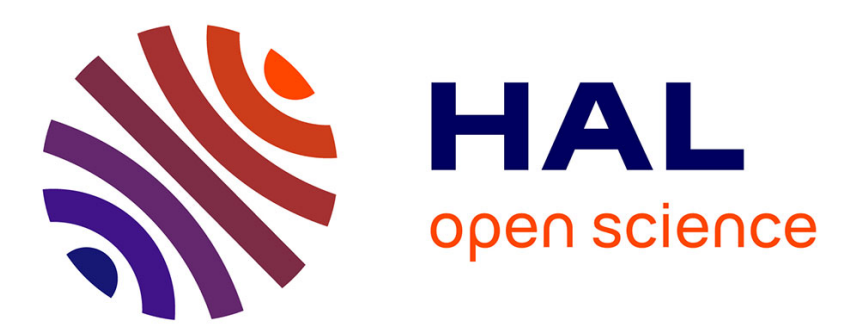

\title{
Reliability Driven Standardization of Mechanical Seals for Petrochemical Applications
}

Lucio Compagno, Natalia Trapani

\section{To cite this version:}

Lucio Compagno, Natalia Trapani. Reliability Driven Standardization of Mechanical Seals for Petrochemical Applications. IFIP International Conference on Advances in Production Management Systems (APMS), Sep 2014, Ajaccio, France. pp.455-462, 10.1007/978-3-662-44733-8_57 . hal01387288

\section{HAL Id: hal-01387288 \\ https://hal.inria.fr/hal-01387288}

Submitted on 25 Oct 2016

HAL is a multi-disciplinary open access archive for the deposit and dissemination of scientific research documents, whether they are published or not. The documents may come from teaching and research institutions in France or abroad, or from public or private research centers.
L'archive ouverte pluridisciplinaire HAL, est destinée au dépôt et à la diffusion de documents scientifiques de niveau recherche, publiés ou non, émanant des établissements d'enseignement et de recherche français ou étrangers, des laboratoires publics ou privés. 


\title{
Reliability Driven Standardization of Mechanical Seals for Petrochemical Applications
}

\author{
Lucio Compagno and Natalia Trapani \\ Dipartimento di Ingegneria Industriale (D.I.I.), University of Catania \\ Viale Andrea Doria 6, 95125 Catania (Italy) \\ lcompagno@di.unict.it, ntrapani@dii.unict.it
}

\begin{abstract}
Mechanical seals are the most diffuse solution for rotating shaft sealing because of their high safety performances and low maintenance costs. The only requirement to meet high service level is a care in the choice of a sealing system suitable for fluids treated and operating conditions. Mechanical seal manufacturers usually have very large catalogues with a wide mix of products for each use and also offers to their clients customized solutions and maintenance service. This could result in high inventory cost for manufacturers which want to guarantee high maintenance service performances. This study shows a reliability driven methodology to reduce the mix and maintain high performances.
\end{abstract}

Keywords. Mechanical seal, reliability data, standardization, maintenance, life table

\section{Introduction}

Today's challenge in Oil \& Gas (O\&G) industry is to become more "sustainable", that is to produce in a more efficient, economical and ecological way. To obtain this result, production systems require quality products and reliable equipments, able to guarantee high availability and service efficacy and efficiency.

As it is known, a significant proportion of industrial emissions occurs through spurious leaks in process system (fugitive emissions), and particularly from flanges, valves and rotating shafts. Fugitive emissions from European refineries were quantified up to 10,000 tons of dangerous substances per year $[1,2]$. The primary purpose of a sealing system is to avoid a fluid loss to protect the environment from pollution due to hazardous substances and mechanical seals are the most diffuse solution for rotating shaft sealing because of their high safety performances and low maintenance costs.

A careful selection of mechanical seals, which requires an analysis of fitness for service (i.e. treated fluid, operating conditions), regular inspection and maintenance are the minimum requirements to obtain high performances [3], i.e. high reliability and low level of VOC (Volatile Organic Compound) emissions [1]. The concept of Best Available Techniques (BAT) was introduced as a key principle in the European IPPC (integrated Pollution Prevention and Control) Directive [4]. In this Directive the 
word 'Techniques' includes both the technology used and the way in which the installation is designed, built, managed, maintained, operated and decommissioned according to a lifecycle management approach.

The selection criteria is often based on technical standards edited by API (American Petroleum Institute), such as API 682 [5] and ISO 21049 [6], EPA (Environmental Protection Agency), such as Method 21 [7], or ESA (European Sealing Association) [1].

In order to satisfy customer needs, manufacturers have developed very large catalogues with a wide mix of products for each use and also customized solutions, and they usually offers to their clients also the maintenance service.

For manufacturers which want or have (i.e. in a global service contract) to guarantee high maintenance service performances (as it is known [1], some solutions generically have a lower Total Emission Level/Lifecycle cost ratio), this could result in high inventory costs but also in higher production costs and maintenance time. In literature there are a lot of papers that define methods to estimate assets reliability and useful life left, in order to support condition based maintenance and prognostics. Most interesting is the GAMM method proposed by Barbera et al. [8], which uses a graphical approach based on a nonparametric estimation of reliability function using historical data; Abiri-Jaromi et al. [9] use an operational research approach to optimize maintenance expected costs; other methods to assess remaining useful life use knowledgebased approach (expert and fuzzy), life expectancy models (stochastic and statistical), Artificial Neural Networks and Physical, showing that the research on how estimate reliability of in service components is still popular $[10,11]$ and a unique solution method is not available.

In order to give a more efficient maintenance service and to reduce inventory and production costs for a mechanical seal manufacturer, a statistical data analysis approach was defined to obtain a standardization of installed base driven by operational conditions and reliability performances.

\section{Case study}

The mechanical seal manufacturer has an installed base of 3,846 items in 8 plants of different clients. The seals can be classified into two macro categories (single or double) which generates 9 families and 21 different typologies (see Fig. 1). 


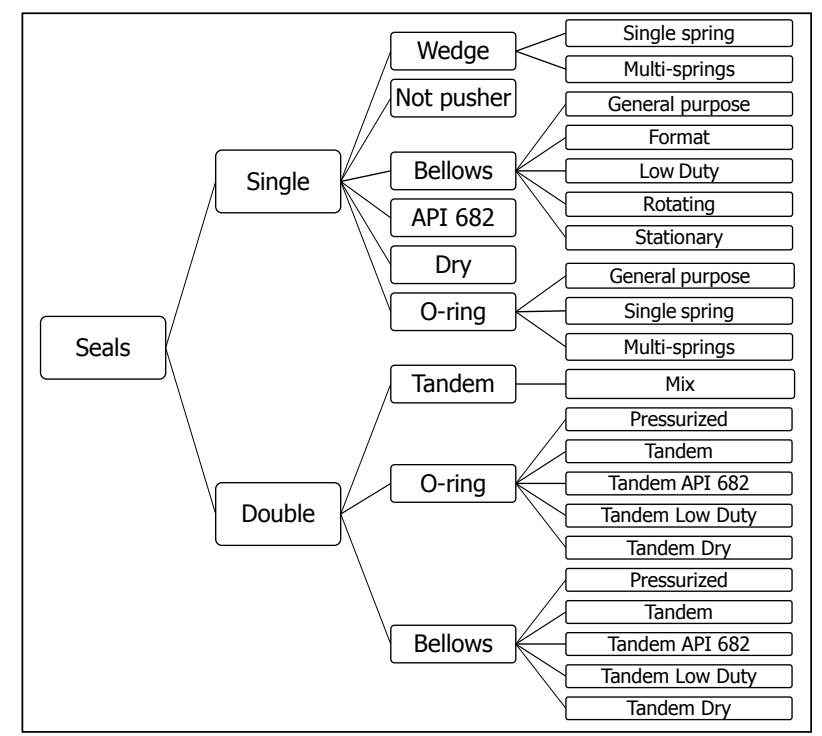

Fig. 1. Classification of seals into families and typologies

The installed base operate in different operational conditions that are caused by the potential combinations of the factors specified in Tab. 1.

Table 1. Operational conditions for the installed base

\begin{tabular}{|l|l|l|}
\hline Variable & Values & ID \\
\hline \multirow{2}{*}{ Process fluid } & Hydrocarbon & I \\
\cline { 2 - 3 } & Not hydrocarbon & N \\
\hline \multirow{3}{*}{ Specific mass } & $\gamma \leq 0.5 \mathrm{~kg} / \mathrm{dm}^{3}$ & $\mathrm{D} 1$ \\
\cline { 2 - 3 } & $0.5<\gamma \leq 0.8 \mathrm{~kg} / \mathrm{dm}^{3}$ & $\mathrm{D} 2$ \\
\cline { 2 - 3 } & $\gamma>0.8 \mathrm{~kg} / \mathrm{dm}^{3}$ & $\mathrm{D} 3$ \\
\hline \multirow{2}{*}{ Temperature } & $\mathrm{T} \leq 200^{\circ} \mathrm{C}$ & $\mathrm{T} 1$ \\
\cline { 2 - 3 } & $\mathrm{T}>200^{\circ} \mathrm{C}$ & $\mathrm{T} 2$ \\
\hline \multirow{2}{*}{ Pressure } & $\mathrm{P} \leq 50 \mathrm{bar}$ & $\mathrm{P} 1$ \\
\cline { 2 - 3 } & $\mathrm{P}>50 \mathrm{bar}$ & $\mathrm{P} 2$ \\
\hline
\end{tabular}

\section{Methodology}

The methodology for the research is composed of three phases:

1. Installed mechanical seals census, to verify the correct classification according to Fig. 2 and the completeness of operational data according to Table 1;

2. Failure data analysis of seals typology, using Life Table technique [12] for assessing a "MTTF Family" (Mean Time To Failure) inside the present database;

3. Identify, within Families with similar application field, the most reliable and verify if it can substitute the others. 


\subsection{Mechanical seals census.}

Having verified the inability to perform statistical analysis on the failures suffered by each item, due to the very low number of single item failure data that would make non-significant the results of the analysis, the Company was required to group seals in uniform classes. This consolidation has led to the definition of 35 families containing seals with similar structural characteristics and service conditions.

The operational conditions database was analyzed in order to verify the completeness of information. Unfortunately the database had complete information only for 1,968 items of the 3,846 installed items $(51.2 \%, 26$ families) with a significant reduction of the useful data. For the operational conditions a codification was defined based on operational data defined in Table 1, thus obtaining 21 codes for dual seals and 23 ones for single seals, e.g. DCRND3T1P1 that is a Dual (D), Cartridge (CR), process fluid not hydrocarbon (N), fluid specific mass $\gamma>0.8 \mathrm{~kg} / \mathrm{dm}^{3}$ (D3), process temperature $T$ $\leq 200{ }^{\circ} \mathrm{C}(\mathrm{T} 1)$, process pressure $\mathrm{P} \leq 50 \mathrm{bar}(\mathrm{P} 1)$.

\subsection{Failure Data Analysis}

The Company provided the records of the dates of failure for each item, surveyed in 64 months, stating the causes of failure identified through a Root Cause Analysis (RCA).

The reliability analysis is based on the evaluation of failure times of items that are part of each family using Life Table theory to exploit as statistically significant also the reliability data of seals that have never failed in the observation period.

The data provided by the Company have the following characteristics:

1. the installation period is known for each component, but not the exact date of installation, then there are doubts on the "service start date";

4. seals are installed at different times and at each failure they were replaced with different seals (new or reconditioned); assuming that the reconditioning is able to return the seal "as new" it is as if, for any fault, a new component was installed;

5. dates of failure are note from 1 January 2006 to 30 April 2011 (64 months);

6. many components didn't fault in the period of observation.

Therefore, the data cannot be considered to be complete and adequate to run a "classical" statistical analysis. This led to the decision of executing an analysis using the Life Table methodology which allows to use data relating to seals that have never failed and data relating to the last period of service (from the last failure to April 30, 2011 ) by treating them as "censored data".

The Life Table is a table of extended frequency that, at discrete time intervals, counts the number of items still running at the beginning of the interval $(\mathrm{Nr})$, of those failed in a period ( $\mathrm{Nf}$ ), and of those no longer controllable (e.g. lost to control or censored, $\mathrm{Nc}$ ) to assess the elements at risk $\mathrm{Ne}$, by the formula: $\mathrm{Ne}=\mathrm{Nr}-\mathrm{Nc} / 2$.

Using this technique it is possible to reach reliable estimates of the four main functions for the study of the life of a component (survival function, probability den- 
sity function, failure rate, MTTF). The minimum size required for the analysis is 30 elements, including fault data and censored data.

In table 2 the life table of a dual seal family (DOTMS) is reported. The table shows all the variables that can be calculated (the calculated standard error often show very low values).

Table 2. Life table for DOTMS family

\begin{tabular}{|c|c|c|c|c|}
\hline $\begin{array}{c}\text { Int. Start } \\
\text { [days] }\end{array}$ & $\begin{array}{l}\text { Nr. Items } \\
\text { running }\end{array}$ & $\begin{array}{c}\mathrm{Nr} . \\
\text { censored }\end{array}$ & $\begin{array}{c}\mathrm{Nr} . \\
\text { exposed }\end{array}$ & $\begin{array}{c}\text { Nr. } \\
\text { Dead }\end{array}$ \\
\hline 0 & 90 & 9 & 85.5 & 21 \\
\hline 250 & 60 & 3 & 58.5 & 13 \\
\hline 500 & 44 & 3 & 42.5 & 9 \\
\hline 750 & 32 & 0 & 32.0 & 4 \\
\hline 1000 & 28 & 4 & 26.0 & 6 \\
\hline 1250 & 18 & 1 & 17.5 & 3 \\
\hline 1500 & 14 & 1 & 13.5 & 2 \\
\hline 1750 & 11 & 11 & 5.5 & 0 \\
\hline $\begin{array}{l}\text { Int. Start } \\
\text { [days] }\end{array}$ & $\begin{array}{l}\text { Survived } \\
\text { fraction }\end{array}$ & $\begin{array}{l}\text { Cum. Survived } \\
\text { fraction }\end{array}$ & PDF & $\begin{array}{l}\text { Failure } \\
\text { rate }\end{array}$ \\
\hline 0 & 0.75439 & 1.00000 & 0.00098 & 0.0011 \\
\hline 250 & 0.77778 & 0.75439 & 0.00067 & 0.0010 \\
\hline 500 & 0.78824 & 0.58674 & 0.00050 & 0.0009 \\
\hline 750 & 0.87500 & 0.46249 & 0.00023 & 0.0005 \\
\hline 1000 & 0.76923 & 0.40468 & 0.00037 & 0.0010 \\
\hline 1250 & 0.82857 & 0.31129 & 0.00021 & 0.0008 \\
\hline 1500 & 0.85185 & 0.25793 & 0.00015 & 0.0006 \\
\hline 1750 & 0.90909 & 0.21972 & - & - \\
\hline
\end{tabular}

The input data for the construction of the life table in this work are the times between repair and the service interval of items lost to control (censored data), according to the following assumptions:

1. installation date was considered to overlap the last failure date available in 2005, or the date of $01 / 01 / 2006$ for all those items whose installation was before 2006;

2. if the item has no faults until 30 April 2011, it was assumed a service period overlapping the entire period of observation;

3. for items that have unknown installation period, the first failure date was considered as installation date.

A goodness-of-fit test for the PDF of each family was then executed by a statistical software application to determine whether it follows a known theoretical distribution (exponential, normal,...). Most of them are normally distributed, some of them are exponentially distributed, as shown in Fig. 2. 

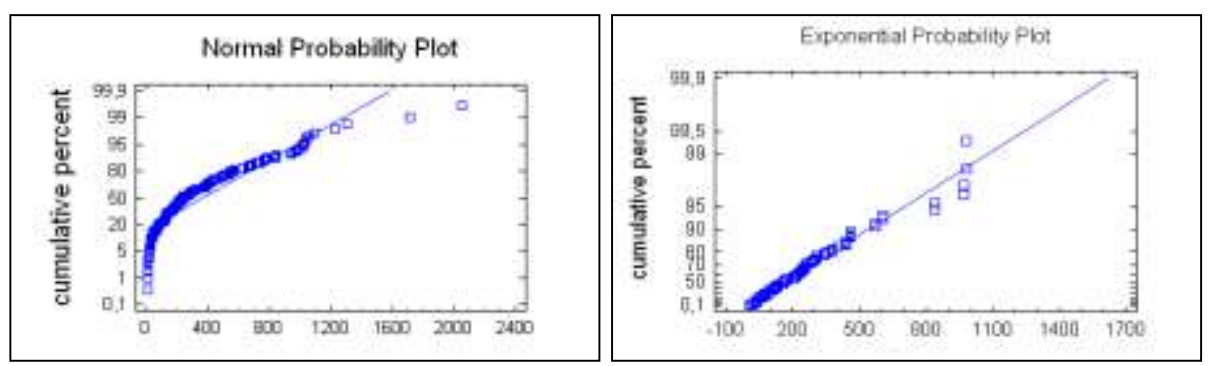

Fig. 2. Goodness of fit test of probability density function for two sets of data

In any case it is possible to calculate the MTTF using the formula (2):

$$
\mathrm{MTTF}=\sum_{\mathrm{k}=1}^{\mathrm{n}} \mathrm{t}_{\mathrm{k}} \cdot \mathrm{f}_{\mathrm{k}}(\mathrm{t}) \cdot \Delta \mathrm{t}_{\mathrm{k}}
$$

where $t_{k}$ is the mean value of the $\Delta t_{k}$ interval and $f_{k}(t)$ is the interval estimation of the PDF $\mathrm{f}(\mathrm{t})$. The MTTF value will be the base for standardization.

\subsection{Standardization}

Crossing the MTTF data with the seals operational conditions it is possible to establish which families are more reliable for each service (operational conditions as specified in Table 1 and paragraph 3.1), as shown in Fig. 3.

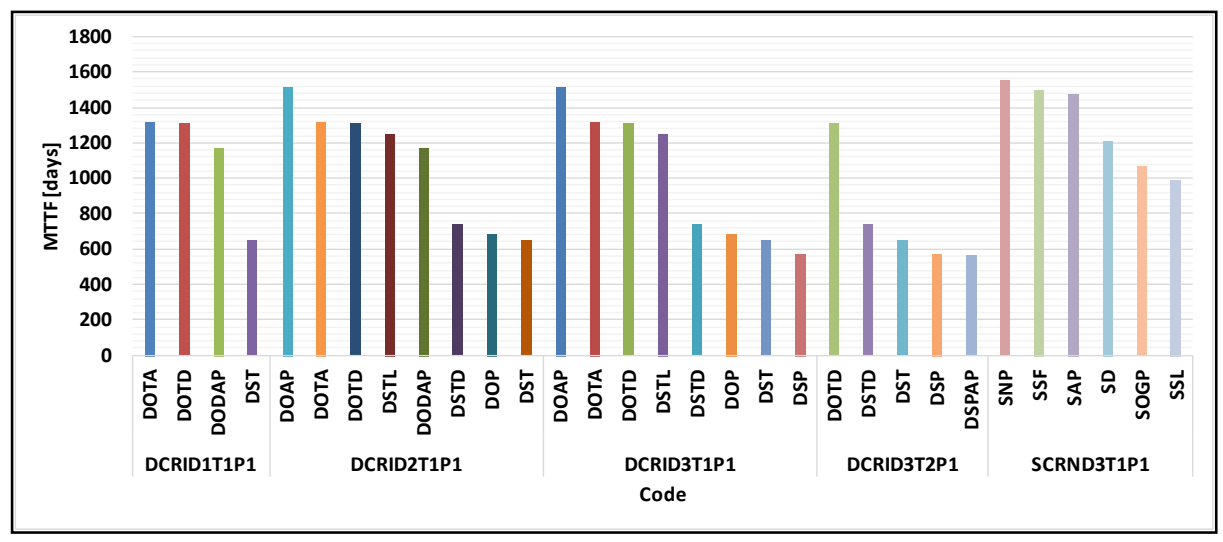

Fig. 3. Families MTTF vs construction and operational conditions

\section{Discussion}

Analysis of Figure 3 allows to establish that for the same range of operational conditions the manufacturer proposes from five to eight different seal families solutions but from the MTTF analysis it is clear that only a few of these can be considered 
reliable in the specific range, e.g. considering the code DCRID3T1P1 four of the installed families have a MTTF less than 800 days and four over 1200 days. The substitution of less reliable seals with the more reliable ones could generate benefits both for the manufacturer who could significantly reduce his catalogue and spare parts inventory with related costs, and for the customer who obtains reduced downtimes, reduced production costs, reduced potential environmental costs due to the better control of fugitive emissions, reduced seals maintenance and repair costs.

The cumulative results of standardization is synthesized in table 3 .

Table 3. Seal families replacement as effect of standardization

\begin{tabular}{|c|c|c|c|c|c|}
\hline Old Family & MTTF old [d] & ITEM Nr. & Total Item & New Family & MTTF new [d] \\
\hline DOTA & 1318 & 161 & \multirow{7}{*}{450} & \multirow{7}{*}{ DOAP } & \multirow{7}{*}{1512} \\
\hline DOTD & 1310 & 97 & & & \\
\hline DSTL & 1246 & 9 & & & \\
\hline DODAP & 1173 & 61 & & & \\
\hline DSTD & 741 & 26 & & & \\
\hline DOP & 689 & 48 & & & \\
\hline DST & 645 & 48 & & & \\
\hline SD & 1210 & 11 & \multirow{3}{*}{115} & \multirow{3}{*}{ SSF } & \multirow{3}{*}{1498} \\
\hline SOGP & 1068 & 8 & & & \\
\hline $\mathrm{SSL}$ & 986 & 96 & & & \\
\hline DSP & 575 & 56 & \multirow{2}{*}{81} & \multirow{2}{*}{ DOTA } & \multirow{2}{*}{1318} \\
\hline DSPAP & 560 & 25 & & & \\
\hline \multicolumn{2}{|c|}{ Total suggested replacement } & 646 & 646 & & \\
\hline
\end{tabular}

The overall results show that from 26 seal families it was suggested to reduce to only 16 families; the seal families replacement, that will be executed gradually (at the first maintenance intervention of each item), is referred to 646 item of 13 families which could be replaced by seal of only the three most reliable families specified in Table 3. In some cases, e.g. DOTA replacement of DSP or DSPAP generate a MTTF more than double, with obvious advantages for the reliability of the equipment.

\section{Conclusions}

Standardization effects are immediately visible both for the producer and customers. For the former in terms of stock costs reduction thanks to an increased interchangeability of spare parts which allows to reduce the size of the order quantity maintaining the same level of risk; for the customers in terms of increased reliability and availability of rotating shafts on which they are installed, with a direct effect on people and environment safety. 
The manufacturer also experimented other less tangible benefits which consist of a greater maintenance specialization, a production mix reduced with benefits on maintenance lead time, customer service level, production lead time and ultimately lower costs of production.

Further studies on the long range effects of the suggested standardization on asset management costs will be probably available after a new census of the current installed base.

\section{References}

1. ESA Publication $N^{\circ}$ 014/09: Sealing Technology - BAT guidance note. European Sealing Association (2009)

2. Onat, A.: A review of fugitive emissions. Sealing technology, October (2006).

3. Huebner, M. B., Buck, G. S., and Azibert, H. B.: Advancements In Mechanical Sealing API 682 Fourth Edition". In: Proceedings of the Twenty Eight Pump Users Symposium September 24-27, Houston, Texas (2012)

4. Directive 2008/1/EC of the European Parliament and of the Council of 15 January 2008 concerning integrated pollution prevention and control (Codified version), Official Journal L 24, 29.1.2008, p. $0008-0029$ (2008).

5. API Standard 682, Fourth Edition: Pumps - Shaft Sealing Systems for Centrifugal and Rotary Pumps. American Petroleum Institute, Washington D.C. (2014)

6. ISO/FDIS 21049:2011(E): Pumps - Shaft Sealing Centrifugal and Rotary Pumps. International Standard Organization, Geneva, Switzerland (2011).

7. EPA Method 21, Determination of volatile organic compound leak. Code of Federal Regulations. Title 40, Part 60, Appendix A. Washington, DC, USA.

8. Barberá, L, Crespo, A., Viveros, P., and Stegmaier, R.: A case study of GAMM (Graphical Analysis for Maintenance Management) applied to water pumps in a sewage treatment plant, Chile. In: Proceeding of 2nd IFAC A-MEST Workshop "Maintenance for Dependability, Asset Management and PHM" November 22-23, 2012 - Seville, Spain (2012)

9. Abiri-Jahromi, A., Parvania, M., Bouffard, F., and Fotuhi-Firuzabad, M.: A Two-Stage Framework for Power Transformer Asset Maintenance Management - Part I: Models and Formulations". In: IEEE Transactions on Power Systems, 28 (2), 1395-1403 (2013)

10. Si, X. S., Wang, W., Hu, C. H., and Zhou D. H.: Remaining useful life estimation - A review on the statistical data driven approaches". European Journal of Operational Research, 213, 1-14 (2011)

11. Sikorska, J. Z., Hodkiewicz, M., and Ma, L.: Prognostic modelling options for remaining useful life estimation by industry. Mechanical Systems and Signal Processing, 25, 1803$1836(2011)$

12. Cox, D.R.: Regression models and Life-Table. J R Stat Soc B, 34 (2), 187-220 (1972) 